\title{
MODELAGEM DAS PROPRIEDADES MECÂNICAS DE TUBOS DE AÇO UTILIZANDO REDES NEURAIS ARTIFICIAIS*
}

\author{
Ramon Santos Corrêa ${ }^{1}$ \\ Patricia Teixeira Sampaio ${ }^{2}$ \\ Antônio Pádua Braga ${ }^{3}$
}

\section{Resumo}

Com a descoberta de poços de petróleo cada vez mais profundos, as tolerâncias das propriedades mecânicas dos tubos de aço utilizados para este fim estão mais restritas. Somando-se a isso, o mercado pressiona por redução de custos e agregação de valor nos produtos ofertados. Por outro lado, a maturidade de interconexão alcançada pelos sistemas industriais, permitiu a disponibilização de dados mais precisos dos processos e a utilização de ferramentas computacionais avançadas de análise e modelagem de dados. Este trabalho tem como objetivo prever as propriedades mecânicas dos tubos após o processo de revenimento, a partir da composição química do aço, parâmetros dimensionais dos tubos e parâmetros do processo. O acompanhamento on-line da tendência das propriedades mecânicas permitiu uma operação preventiva no forno de revenimento, possibilitando a redução do lead time do processo, visto o tempo médio de 2 dias para o recebimento dos resultados do laboratório. A definição pela utilização das Redes Neurais Artificiais se baseou em trabalhos relacionados ao tema e casos de sucesso aplicados na indústria. Observou-se que os resultados obtidos a partir dos modelos obtiveram índices de assertividade superiores aos de outras técnicas utilizadas para este fim. Além disso, foi possível a criação de um único modelo para cada propriedade mecânica considerando todas as famílias de aço produzidas na Vallourec, facilitando os processos de calibração e sustentabilidade dos modelos.

Palavras-chave: Redes neurais; Propriedades mecânicas; Processo de revenimento; Tubos de aço.

\section{MECHANICAL PROPERTIES MODEL OF STEEL TUBES USING NEURAL NETWORK}

\section{Abstract}

The discovery of oil wells in very deep layers requires restricted tolerances of the mechanical properties of the steel tubes used for this purpose. Besides that, market request for cost savings and added value in the products offered. On the other hand, as the industrial information systems are becoming even more interconnected and mature, they have been capable to provide more accurate process data and also to use the advanced computational tools for data analysis and modeling. This work aims to predict the mechanical properties of the steel tubes after tempering process, using the steel chemical composition, dimensional parameters and process parameters. The online monitoring of the mechanical properties trend allowed a preventive operation in tempering furnace, enabling a reducing in the lead time of the process, as the average time of 2 days for the laboratory results. The use of Neural Networks (NN) was supported by works related to this subject and by successful business cases in the industry. The results obtained by the use of NN models were more assertive than other techniques used for same purpose. Besides that, a single NN model for each mechanical property, considering all steel families produced in Vallourec, made the model calibration process and its sustainability much easier.

Keywords: Neural networks; Mechanical properties; Tempering process; Steel tubes.

1 Engenheiro de Controle e Automação, Mestrando da Universidade Federal de Minas Gerais, Belo Horizonte, Minas Gerais, Brasil.

2 Engenheira Eletricista, MSc., Engenheira da Vallourec Tubos do Brasil, Belo Horizonte, Minas Gerais, Brasil.

3 Engenheiro Eletricista, Dr., Professor Titular da Universidade Federal de Minas Gerais, Belo Horizonte, Minas Gerais, Brasil. 


\section{INTRODUÇÃO}

Os tubos de aço são classificados quanto à sua utilização de acordo com as características dimensionais, acabamento superficial e suas propriedades mecânicas. O conhecimento adequado das propriedades mecânicas possibilita otimizar o desenvolvimento e ampliar a aplicabilidade dos tubos.

Para obtenção de uma combinação desejável das propriedades mecânicas do tubo, - mesmo é submetido aos processos de tratamento térmico, conhecidos como têmpera e revenimento. A têmpera é composta pelas etapas de aquecimento e de esfriamento brusco, que visam aumentar a dureza dos aços. O processo de revenimento consiste em reaquecer a peça temperada a uma determinada temperatura por certo período de tempo, corrigindo a fragilidade e as tensões internas do aço, resultantes do processo de têmpera. A interação das variáveis tempo e temperatura, somadas à composição química do aço é o que determinará as propriedades mecânicas do aço temperado e revenido [1]. Apesar da simplicidade do processo de revenimento, os fenômenos envolvidos na mudança microestrutural do aço torna o controle do processo complexo. Atualmente o controle é baseado em alguns parâmetros que permitem a escolha adequada do tempo e temperatura. No entanto, Hollomon e Jaffe perceberam que diferentes combinações de tempo e temperatura produziam a mesma propriedade mecânica [2].

Nas últimas décadas, vários trabalhos têm sido realizados para prever as propriedades mecânicas de aços, com destaque para o desenvolvimento de modelos baseados em regressões lineares múltiplas, redes neurais artificiais e sistemas híbridos neuro-fuzzy. Nos trabalhos de Jones et al. [3] e de Takahashi [4], as propriedades mecânicas dos aços foram previstas utilizando-se técnicas de regressão múltipla linear e redes neurais artificiais (RNA). As técnicas de análise de regressão apresentaram desempenhos similares, no entanto a RNA apresentou desempenho superior. Chen e Linkens [5] utilizaram sistemas híbridos neuro-fuzzy para a predição das propriedades mecânicas com resultados satisfatórios. Takahashi [4] comparou os resultados obtidos por sistemas neuro-fuzzy com as RNAs e observou um desempenho similar. Considerando-se a complexidade das relações entre entradas e saídas dos modelos para predição das propriedades mecânicas, o uso das redes neurais artificiais neste trabalho apresentou-se como uma abordagem robusta e com desempenho superior aos modelos atuais, especialmente na região de maior frequência de amostragem das variáveis de entrada.

O objetivo deste trabalho foi desenvolver modelos utilizando redes neurais artificiais para a predição das propriedades mecânicas, tais como, limite de escoamento, resistência à tração e dureza, possibilitando a atuação de forma preventiva na operação do forno de revenimento.

\section{MATERIAIS E MÉTODOS}

As propriedades mecânicas limite de escoamento (LE) e resistência à tração (RT) são obtidas por meio de ensaios de tração. Estes ensaios consistem em aplicar um esforço crescente de tração na direção axial de um corpo de prova até a sua ruptura. Durante o ensaio são registradas as tensões aplicadas ao corpo de prova e a deformação correspondente e, ao final, é obtida a curva de tensão versus deformação do material. O LE é definido como a maior tensão que pode ser aplicada a um material antes que ele comece a se deformar permanentemente e a RT é 
definida como a tensão máxima que o material resiste, quando submetido a um esforço de tração. A propriedade mecânica dureza (DZ) é obtida por meio de ensaios de dureza. Estes ensaios consistem em produzir pequenas marcas feitas pelo penetrador do durômetro, quantificando a dureza do material em função da impressão produzida no mesmo.

As redes neurais artificiais (RNAs) são modelos computacionais que simulam o comportamento dos sistemas nervosos biológicos. São compostas por unidades de processamento simples (neurônios) e possuem a capacidade de aprender por meio de exemplos e de generalizar a informação aprendida [6].

O algoritmo Levenberg-Marquardt (LM), utilizado nos modelos de predição das propriedades mecânicas desenvolvidos neste trabalho, é o algoritmo de segunda ordem mais utilizado para o treinamento de uma rede do tipo feedforward, devido à sua velocidade de convergência e baixa complexidade. Além da aproximação da matriz Hessiana, o algoritmo LM modifica o método de Newton incluindo um fator $\mu$ responsável pelo ajuste do tamanho do incremento realizado pelo algoritmo. Desta forma, quando o valor de $\mu$ se aproxima de zero, o algoritmo se torna o método de Newton utilizando a aproximação da matriz Hessiana e, quando o valor fica muito grande, ele se torna o método gradiente descendente. Desta forma, a função objetivo é sempre minimizada a cada iteração do algoritmo [7].

Durante o treinamento de uma rede neural, o objetivo principal é gerar uma rede que produza um baixo erro de aprendizado e, principalmente, que seja capaz de responder adequadamente à apresentação de novos dados. Um método considerado eficiente para aperfeiçoar a generalização de uma rede é a regularização bayesiana, que se baseia na restrição dos valores dos pesos da rede. Este método consiste em adicionar um termo de penalização (regularização) à função objetivo de modo que o algoritmo faça com que os parâmetros irrelevantes sejam convergidos para zero, reduzindo o número efetivo de parâmetros utilizados.

O trabalho deste artigo foi desenvolvido na área da Laminação Automática da Vallourec Tubos do Brasil. Para o desenvolvimento dos modelos, foram coletados resultados dos ensaios de limite de escoamento, resistência à tração e dureza e os parâmetros do processo produtivo (Tabela 1) das respectivas amostras. Como o comportamento térmico de cada família de aço é diferente, as amostras foram agrupadas em famílias de aço. Como pode ser visto na Figura 1, o numero de amostras por família foi bem distinto, o que poderia tendenciar o treinamento dos modelos.

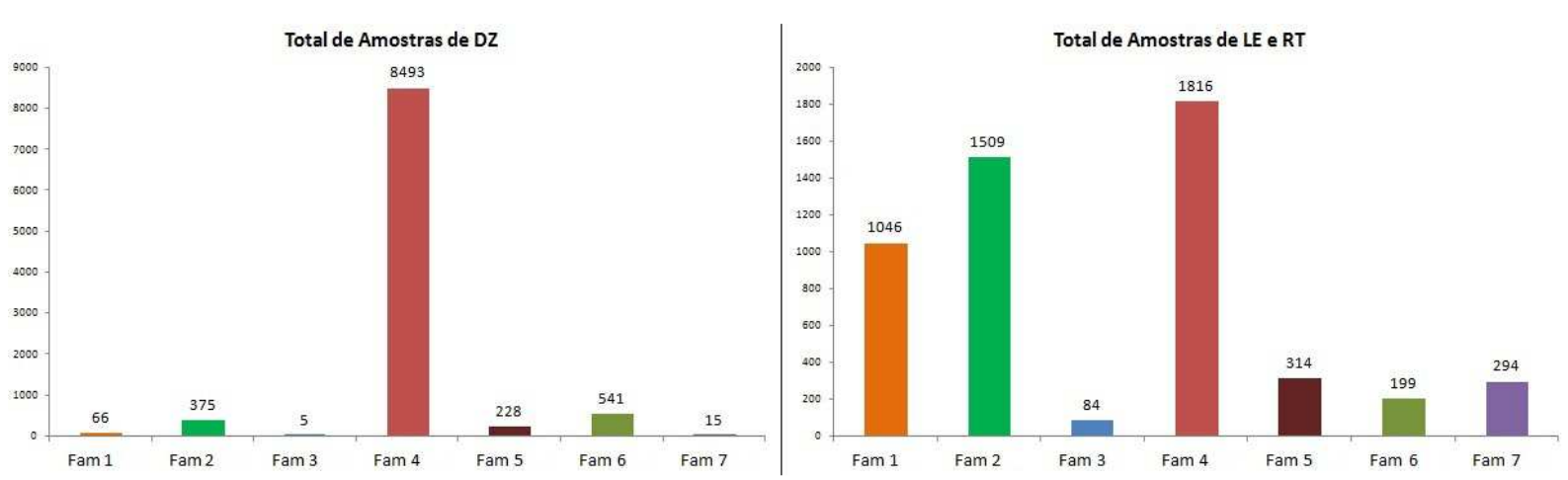

Figura 1: Total de amostras utilizadas nos modelos LE, RT e DZ.

Para resolver o problema de baixa amostragem de algumas famílias, foi utilizada a técnica bagging (bootstrap aggregating), que consiste em um método ensemble criado por Breiman [8] e baseia-se na criação de réplicas bootstraps. As réplicas 
bootstraps são subconjuntos gerados aleatoriamente e com reposição a partir do conjunto de treinamento original. Os métodos ensembles são baseados na ideia de diversidade, isto é, quando decisões independentes e diferentes são combinadas, erros aleatórios se cancelam e decisões corretas são reforçadas, obtendo-se um melhor desempenho do que um único modelo.

No entanto, como a produção das famílias de aço era muito desbalanceada, para garantirmos a apresentação de dados de todas as famílias nas bases de treinamento e validação, separamos os dados por família de aço. Para a base de treinamento foram utilizados $70 \%$ dos dados de cada família e para a validação/teste do modelo neural foram utilizados os $30 \%$ restantes.

Para a definição das variáveis mais relevantes para a previsão das propriedades mecânicas dos aços foram levados em consideração os trabalhos de Takahashi [4], Gorni et al. [9] e Penha [1], e a avaliação de especialistas em metalurgia das equipes de processo e produção da Têmpera da Laminação Automática da Vallourec.

Para encontrar um conjunto reduzido de variáveis de entrada, com mínima redundância entre si e máxima relevância para a saída do modelo, foram realizados testes de correlação cruzada e análise de sensibilidade das variáveis independentes. Foi verificado que a utilização apenas das variáveis: espessura da parede do tubo, composição química do aço, tempo de encharque do forno de revenimento e temperatura média de saída do forno de revenimento, foram suficientes para obter uma boa predição das propriedades mecânicas. No entanto, utilizando como referência o trabalho realizado por Gomes et al. [10], observou-se que a utilização de um parâmetro proposto por Tsuchiyama agregava mais informação do que a combinação das variáveis tempo de encharque e temperatura média do tubo na saída do forno de revenimento. O parâmetro de Tsuchiyama (PTS) propõe a divisão do ciclo térmico em pequenos intervalos, e a cada intervalo tempo a uma determinada temperatura de referência $\boldsymbol{T}_{\boldsymbol{r}}$, calcula-se o parâmetro de Hollomon-Jaffe. No entanto, tanto Tsuchiyama quanto Hollomon-Jaffe propõem relações que descrevem a integral da curva do ciclo térmico.

As variáveis utilizadas nos modelos das propriedades LE, RT e DZ podem ser vistas na Tabela 1.

Tabela 1. Variáveis de entrada dos modelos

\begin{tabular}{lc}
\hline Variável de entrada & Unidade \\
\hline Espessura da parede do tubo & $\mathrm{m}$ \\
\hline $\begin{array}{l}\text { Temperatura média do tubo na saída do Forno de } \\
\text { Revenimento }\end{array}$ & ${ }^{\circ} \mathrm{C}$ \\
\hline Parâmetro de Tsuchiyama & $\%$ \\
\hline Elemento químico 1 & $\%$ \\
\hline Elemento químico 2 & $\%$ \\
\hline Elemento químico 3 & $\%$ \\
\hline Elemento químico 4 & $\%$ \\
\hline Elemento químico 5 & $\%$ \\
\hline Elemento químico 6 & $\%$ \\
\hline Elemento químico 7 & $\%$ \\
\hline Elemento químico 8 & $\%$ \\
\hline
\end{tabular}

Para definição da melhor topologia a ser utilizada, vários testes foram realizados. Após uma análise detalhada dos resultados, optou-se por utilizar o algoritmo Levenberg-Marquardt em conjunto com a regularização bayesiana, a fim de obter 
uma melhor generalização do modelo. Com base também nos resultados, ficou definido que seria desenvolvido um modelo neural para cada propriedade mecânica LE, RT e DZ.

A estrutura das RNAs de previsão do LE e da RT que forneceram os melhores resultados foi similar. As RNAs foram compostas por 1 camada escondida com 12 neurônios e 1 camada de saída com 1 neurônio. Já a estrutura da RNA de previsão da DZ que forneceu melhor resultado foi composta por 1 camada escondida com 21 neurônios e 1 camada de saída com 1 neurônio. Em todos os modelos neurais foram utilizadas as funções de ativação tangente hiperbólica sigmoidal (tansig) nos neurônios da camada escondida e linear no neurônio da camada de saída.

Para melhorar a capacidade de generalização dos modelos com baixa amostragem, foi aplicada a técnica bagging no treinamento das redes, utilizando-se 25 réplicas bootstrap, ou seja, um comitê composto por 25 RNAs. A saída dos modelos foi a média simples dos resultados dos bootstraps. Todas as RNAs do comitê foram geradas com a mesma estrutura e os mesmos parâmetros de treinamento, diferindose apenas no conjunto de treinamento.

\section{RESULTADOS E DISCUSSÃO}

Para avaliar o desempenho dos modelos, foram analisados a média e o desvio padrão dos erros absolutos, a correlação entre os valores reais e os previstos e o percentual dos erros dentro das faixas consideradas desejável e aceitável. Estas faixas foram definidas pelas equipes de processo e de produção da Têmpera da Laminação Automática da VBR, com base na precisão dos resultados dos ensaios mecânicos de laboratório. As faixas de erros definidas para cada modelo estão descritas na Tabela 2.

Tabela 2. Faixas de erros definidas por modelo

\begin{tabular}{llll}
\hline & $\mathrm{LE}$ & $\mathrm{RT}$ & Dureza \\
\hline Desejável & $\leq 20 \mathrm{MPa}$ & $\leq 20 \mathrm{MPa}$ & $\leq 15 \mathrm{HV}$ \\
\hline Aceitável & $\leq 35 \mathrm{MPa}$ & $\leq 35 \mathrm{MPa}$ & $\leq 25 \mathrm{HV}$ \\
\hline Indesejável & $>35 \mathrm{MPa}$ & $>35 \mathrm{MPa}$ & $>25 \mathrm{HV}$ \\
\hline
\end{tabular}

A média e o desvio padrão dos erros absolutos obtidos na validação do modelo de previsão do LE podem ser vistas na Tabela 3, onde são apresentados por família de aços e para o caso geral.

Tabela 3. Estatística dos erros absolutos na validação do modelo do LE

\begin{tabular}{lcccccccc}
\hline & Geral & Fam 1 & Fam 2 & Fam 3 & Fam 4 & Fam 5 & Fam 6 & Fam 7 \\
\hline Erro médio & 11,47 & 7,34 & 13,04 & 12,68 & 18,13 & 8,75 & 10,88 & 6,93 \\
\hline Desvio padrão & 11,26 & 8,35 & 11,06 & 9,23 & 17,22 & 7,09 & 11,48 & 8,86 \\
\hline \multicolumn{7}{c}{ Os valores descritos na tabela estão em MPa. }
\end{tabular}

Na Figura 2 são apresentados os percentuais dos erros de predição do modelo do LE, considerando as faixas: desejável (azul), aceitável (verde) e indesejável (vermelho) e a correlação entre os valores reais e os previstos pelo modelo de predição do LE. 

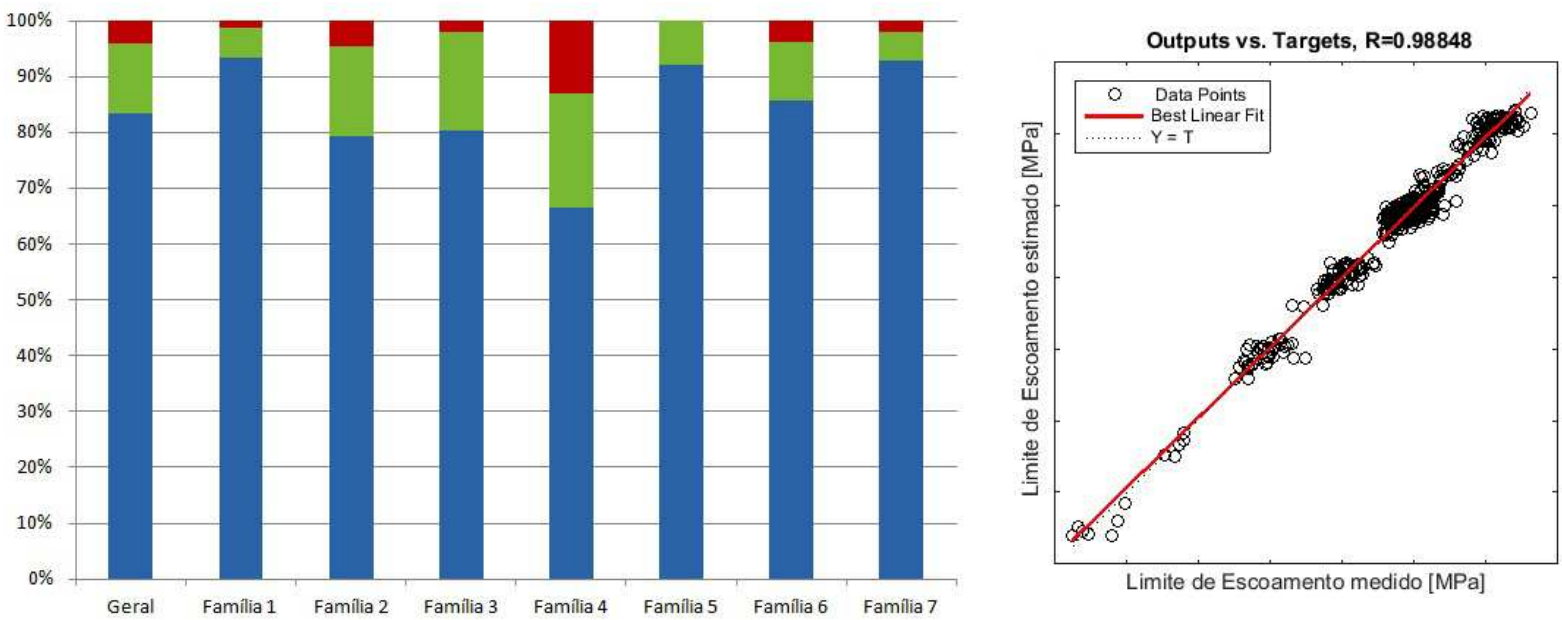

Figura 2: Resultados estatísticos dos erros absolutos do modelo do LE.

A média e o desvio padrão dos erros obtidos na validação do modelo de previsão da RT podem ser vistas na Tabela 4, onde são apresentados por família de aços e para o caso geral.

Tabela 4. Estatística dos erros absolutos na validação do modelo da RT

\begin{tabular}{lcccccccc}
\hline & Geral & Fam 1 & Fam 2 & Fam 3 & Fam 4 & Fam 5 & Fam 6 & Fam 7 \\
\hline Erro médio & 8,72 & 6,19 & 10,79 & 12,52 & 11,83 & 6,63 & 8,28 & 4,43 \\
\hline Desvio padrão & 9,19 & 6,98 & 10,94 & 9,02 & 11,67 & 4,97 & 8,09 & 5,81 \\
\hline \multicolumn{7}{c}{ Os valores descritos na tabela estão em MPa. }
\end{tabular}

Na Figura 3 são apresentados os percentuais dos erros de predição do modelo da RT, considerando as faixas: desejável (azul), aceitável (verde) e indesejável (vermelho) e a correlação entre os valores reais e os previstos pelo modelo de predição da RT.
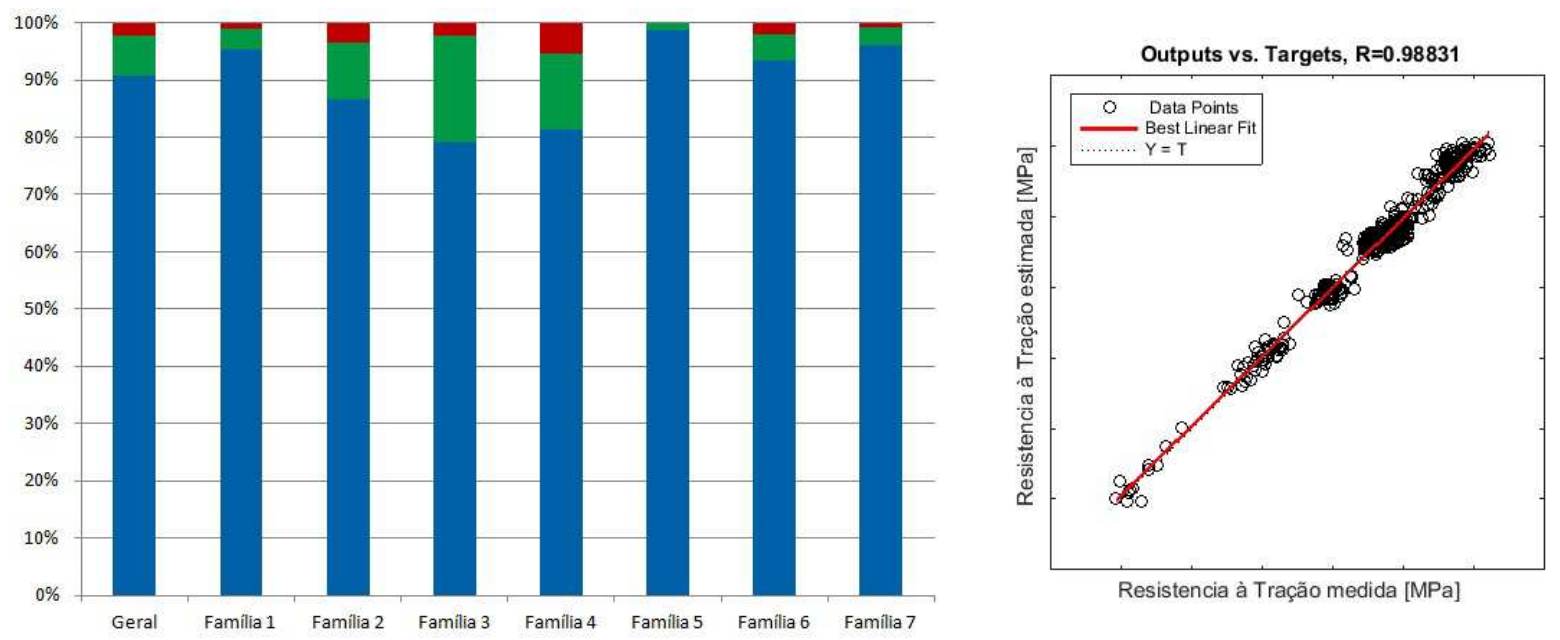

Figura 3: Resultados estatísticos dos erros absolutos do modelo da RT.

A média e o desvio padrão dos erros obtidos na validação do modelo da DZ podem ser vistas na Tabela 5, onde são apresentados por família de aços e para o caso geral.

Tabela 5. Estatística dos erros absolutos na validação do modelo da DZ

\begin{tabular}{lcccccccc}
\hline & Geral & Fam 1 & Fam 2 & Fam 3 & Fam 4 & Fam 5 & Fam 6 & Fam 7 \\
\hline Erro médio & 2,72 & 8,11 & 2,56 & 2,75 & 3,53 & 11,16 & 3,33 & 4,97 \\
\hline Desvio padrão & 3,37 & 13,61 & 2,51 & 3,59 & 3,65 & 3,52 & 7,30 & 4,81 \\
\hline
\end{tabular}

Os valores descritos na tabela estão em $H V$. 
Na Figura 4 são apresentados os percentuais dos erros de predição do modelo da DZ, considerando as faixas: desejável (azul), aceitável (verde) e indesejável (vermelho) e a correlação entre os valores reais e os previstos pelo modelo de predição da DZ.
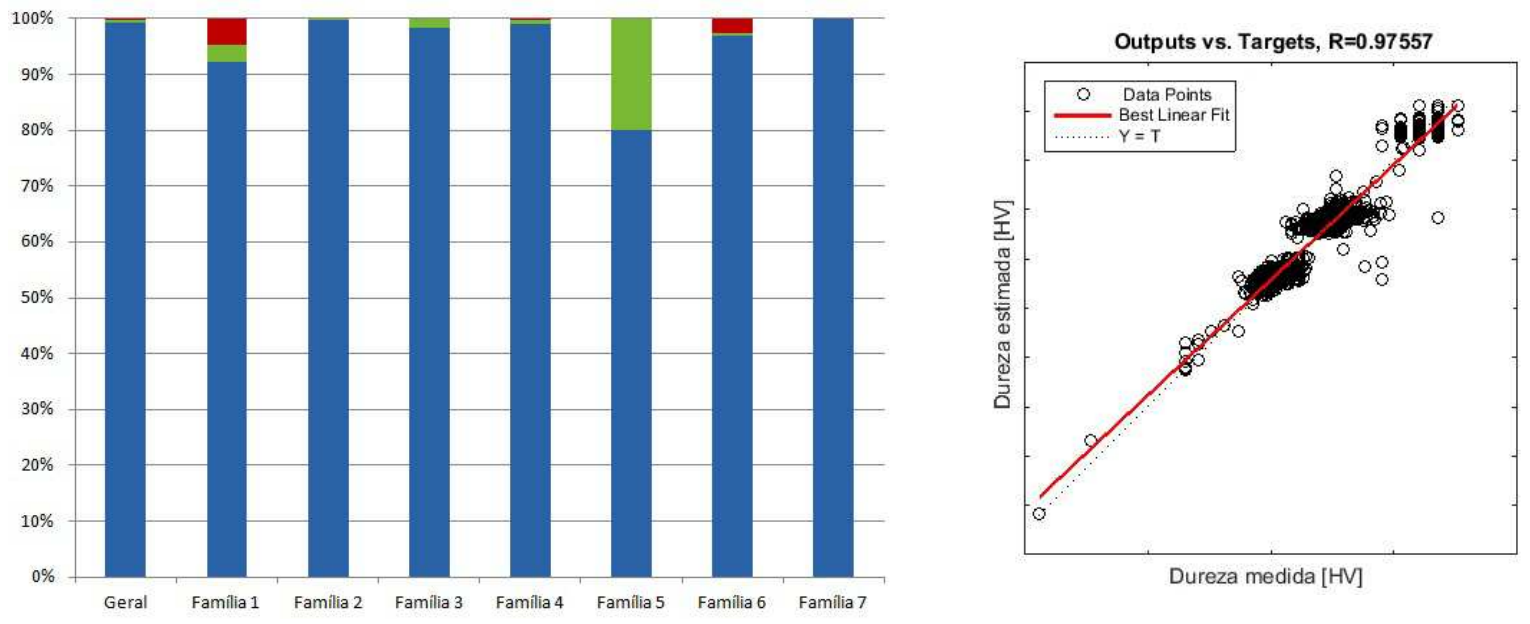

Figura 4: Resultados estatísticos dos erros absolutos do modelo da DZ.

Conforme pode ser observado nas Tabelas 3 e 4, o modelo de previsão da RT apresenta melhor desempenho do que o modelo de previsão do LE. Este fato está associado à dificuldade da medição precisa do LE durante o ensaio de tração e este resultado é compatível com os obtidos por Yang e Linkens [11] e Jones et al. [12]. No entanto, considerando o percentual dos erros absolutos dentro das faixas desejável e aceitável, o que obteve o melhor desempenho foi o modelo de DZ, com resultados superiores a 99\%. Todos os modelos obtiveram alta correlação entre os valores reais e estimados, o que representa elevada assertividade dos modelos.

Pelos resultados, foi observado que algumas famílias de aços que possuíam baixa amostragem, obtiveram um desempenho inferior. Para avaliar a influência da amostragem no desempenho dos modelos, foi feita uma análise dos dados de validação por meio de um estimador multivariado de densidade por kernel (KDE). $O$ KDE é um método não paramétrico usado para estimar a função de densidade de uma variável aleatória $x$, dada uma amostra aleatória de $N$ observações. O KDE foi utilizado para estimar a densidade das amostras de validação com base na densidade das amostras de treinamento. Na Figura 5 é apresentado um gráfico do KDE das amostras de validação do modelo da RT versus a função cumulativa de densidade (CDF) dos erros absolutos maiores que o valor aceitável. Verifica-se um aumento quase exponencial da CDF dos erros para um decréscimo também exponencial do KDE, o que reforça a hipótese de que os erros acima do aceitável estão relacionados com a baixa amostragem.

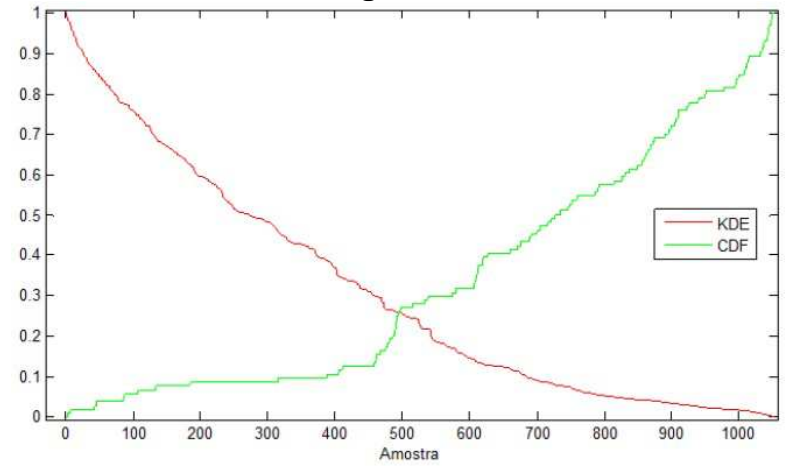

Figura 5: KDE versus CDF dos erros das amostras de validação. 
Para a operacionalização dos modelos foi desenvolvido um módulo, denominado SPPM (Sistema de Predição das Propriedades Mecânicas), integrado ao sistema de rastreamento existente na planta, que calcula para cada tubo o valor de suas propriedades mecânicas, após o processo de revenimento. Os valores estimados pelos modelos são apresentados na tela de operação e em gráficos de controle estatístico do processo (CEP), permitindo o acompanhamento da tendência das propriedades mecânicas. Os resultados das propriedades mecânicas fornecidos pelo laboratório demoram em média 2 dias para chegar à produção. Com esta ferramenta, o operador é capaz de atuar de forma preventiva no forno, a partir da alteração dos parâmetros de setup do mesmo, quando as propriedades mecânicas dos tubos indicarem uma tendência de desvio dos valores de tolerância definidos em cada pedido. Esta atuação pode ser feita on-line, reduzindo o lead time do processo. Na Figura 6 podem-se ver os gráficos de CEP do LE, da RT e da DZ, sendo que em verde estão os valores estimados pelos modelos e em vermelho as tolerâncias definidas pelos clientes.

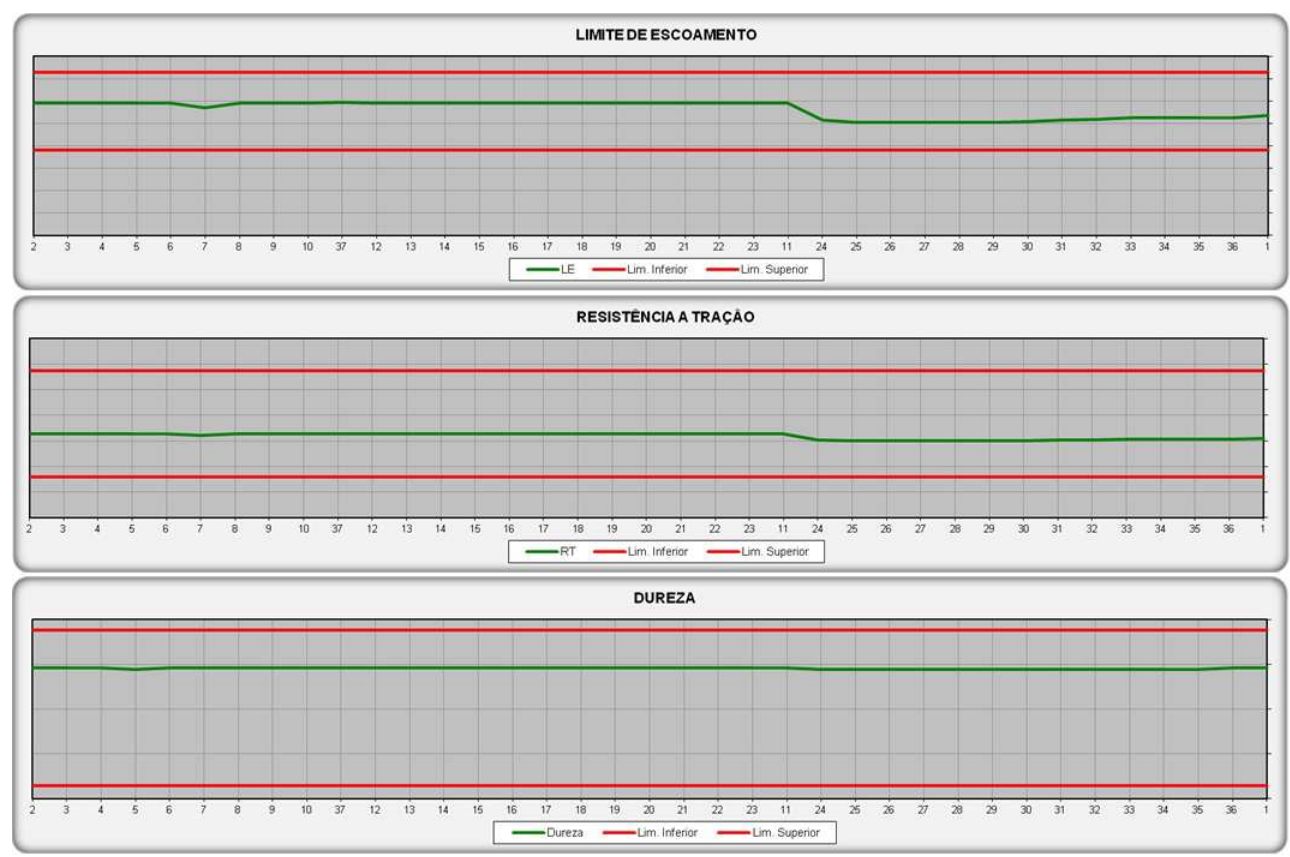

Figura 6: Gráficos CEP das propriedades mecânicas

\section{CONCLUSÃO}

Os resultados obtidos na validação dos modelos comprovaram que a utilização de RNAs para a previsão de propriedades mecânicas é uma alternativa viável e eficiente para a modelagem do processo de revenimento. De acordo com os especialistas em Têmpera da Laminação Automática da Vallourec, o sistema desenvolvido tem fornecido resultados coerentes com os fenômenos metalúrgicos do processo.

Um dos maiores desafios deste trabalho foi desenvolver modelos aplicáveis a todas as famílias de aço produzidas na Vallourec que, além de serem capazes de estimar bem as propriedades mecânicas dos aços, deveriam possuir boa capacidade de generalização. Devido à elevada dependência da amostragem dos dados com o desempenho dos modelos, algumas famílias de aços que possuíam baixa amostragem obtiveram resultados de desempenho inferiores quando comparados com resultados de outras famílias. No entanto, com a utilização de técnicas 
ensemble, foi possível minimizar os efeitos deste desbalanceamento das amostras, obtendo resultados satisfatórios para todas as famílias de aços produzidos na Vallourec.

\section{Agradecimentos}

Agradecemos o apoio técnico dos especialistas em Têmpera da Vallourec Victor Lambertucci e Rafael Braga, fundamentais para a elaboração e validação deste trabalho na Vallourec.

\section{REFERÊNCIAS}

1 Penha RN. Modelo do processo de revenimento por redes neurais [tese de doutorado]. São Paulo: Universidade de São Paulo, Escola de Engenharia de São Carlos; 2010.

2 Hollomon JF, Jaffe LD. Time-temperature relations tempering steel. Transactions of AIME. 1945;162:223-249.

3 Jones DM, Watton J, Brown KJ. Comparison of hot rolled steel mechanical property prediction models using linear multiple regression, non-linear multiple regression and non-linear artificial neural networks. Ironmaking and Steelmaking. 2005; 32:435-442.

4 Takahashi HJ. Predição de Propriedades Mecânicas de Aços de Alta Resistência Microligados Utilizando Técnicas de Inteligência Computacional [dissertação de mestrado]. Coronel Fabriciano: Unileste, Engenharia Industrial; 2006.

5 Chen M, Linkens DA. Hybrid fuzzy modelling using simulated annealing and application to materials property prediction. Proceedings of the Second International Conference on Intelligent Processing and Manufacturing of Materials. 1999;1:109-114.

6 Haykin S. Neural networks: a comprehensive foundation. $2^{\underline{a}}$ edition. New Jersey: Prentice Hall; 1999.

7 Braga AP, Carvalho AC, Ludemir TB. Redes Neurais Artificiais: teoria e aplicações. Rio de Janeiro: Livros Técnicos e Científicos; 2000.

8 Breiman L. Bagging Predictors. Berkeley: University of California; September 1994. Report No.: 421.

9 Gorni AA, Silva MRS, Dolabela JHS. Previsão de Propriedades Mecânicas de Bobinas Laminadas a Quente através de Redes Neurais. Tecnologia em Metalurgia e Materiais, São Paulo. 2009; 5:229-234.

10 Gomes C, Kaiser AL, Bas JP, Aissaoui A, Piette M. Predicting the mechanical properties of a quenched and tempered steel thanks to a tempering parameter. Revue de Métallurgie. 2010; 107:293-302.

11 Yang, YY, Linkens DA. Steel yield strength prediction using ensemble model performance improvement over single neural network model. IPMM 2001 Intelligent Processing and Manufacturing of Materials, 2001; 1:335-346.

12 Jones DM, Watton J, Brown KJ. Comparison of hot rolled steel mechanical property prediction models using linear multiple regression, non-linear multiple regression and non-linear artificial neural networks. Ironmaking and Steelmaking. 2005; 32:435-442. 